\title{
美国城市规划从概念到行动的务实演进 以生态城市为例
}

\author{
The Pragmatic Evolution of Urban Planning from Concept to Act: Eco-city Example
}

张文博 宋彦 邓玲 田敏

Zhang Wenbo, Song Yan, Deng Ling, Tian Min

\begin{abstract}
摘要: 从1970 年代提出以来, 生态城市经历了从构想和概念到目标体系, 再 到具体行动的演进过程, 是美国城市规划理念应用和务实演进的典型代表, 研究其演进规律和发展趋势对总结美国城市发展规律具有重要的理论价值和 现实意义。从发展阶段来看, 生态城市可细分为理念探索, 目标设定和应用, 指标评价体系构建和广泛实践、完善和务实推进四个阶段。在城市规模扩大、 资源环境约束趋紧, 以及各类主体对城市治理诉求增加的背景下, 美国的生 态城市理念也产生了新的内涵和特点, 在目标体系方面, 更加注重经济的生 态化转型、社会进步和以人为本, 更加突出目标体系对行动的指导性和政策 有效性的评价, 强调基于“目标一行动路线”的建设模式, 在建设行动方面, 更加强调行动的针对性和系统性、参与主体的多元化, 以及管理手段的信息化。 总结美国生态城市理念的务实演进规律和发展趋势, 有利于推动中国生态城 市建设, 实现城市发展与资源环境相协调。
\end{abstract}

Abstract: Since 1970s, Eco-cities have experienced the evolution process from concept to evaluation system to action, which is also the epitome of the pragmatic evolution of American urban planning. The paper takes eco-city as an example to study the evolution of urban planning in the USA. Eco-cities have experienced four stages: concept exploration, goal setting, evaluation, perfect and pragmatic promotion. Now the concept of eco-city in the USA has also produced new features and trends: the objective is more focused on ecological transformation, innovation, social communication and affordable housing; the action is more targeted and systematic, and encourages more diverse groups to participate. Learning from these experiences is conducive to promoting China's eco-city construction. By summarizing the rules of pragmatic evolution of eco-city and following the development trend, the cities in China will achieve the goal of sustainable development.

关键词：生态城市；务实演进；评价体系；目标一行动路线

Keywords: Eco-city; Pragmatic Evolution; Evaluation System; Objective-Action Route

国家社科基金重点项目“城市生态文明协同创新体系研究” (13AZD076) ; 国家自 然科学基金海外及港澳学者合作研究基金项目 (51728802)

\section{引言}

1970 年代是美国城市规划演进的重要分水岭, 在此之前, 以物质形态设计为主的传统城市规划是 城市规划的主流，而 1970 年以后，美国的城市由快 速扩张阶段进入转型和调整阶段, 高速公路建设、清 除贫民窟和城市更新运动等引起了广泛的社会冲突, 城市管理者和学者都迫切地希望通过调整城市规划 来缓解甚至解决城市发展中出现的社会治理、环境污 染等问题。在这一背景下, 生态城市、宜居城市等新 理念纷纷涌现, 美国的城市规划也随之进人了由概念 到行动的务实演进阶段。在这一过程中, 以推动城市 可持续发展为主要目标的生态城市理念无疑最具代 表性和典型性, 从 1970 年代提出以来, 生态城市经 历了从概念到目标体系, 再到具体行动的务实演进过 程, 成为美国城市规划理念发展和实践的亲历者和见 证者。进人 21 世纪后, 美国城市对可持续发展的高 度关注更使得生态城市建设成为实现可持续发展和 宜居社区的重要途径, 生态城市理念已逐步成为城市 规划的重要原则, 其内涵更加丰富, 目标设定和行 动设计也更加务实。因此, 本文试图以生态城市为例, 通过梳理和分析其演进和发展历程, 探寻美国城市规 划理念由概念到行动的务实演进规律, 以期能为中国 城市规划研究的应用和实践提供经验和借鉴。

作者: 张文博, 上海社会科学院生态与可持续发展研究所, 助理研究员; 北卡罗来纳大学教堂山分校联合培养博士。wenboz00@163.com 宋彦 (通信作者), 深圳大学城市规划系, 教授; 北卡罗来纳大学教堂山分校城市与区域规划系, 终身教授。ys@email.unc.edu 邓玲, 四川大学经济学院, 教授, 博士生导师。denglingprof@163.com 田敏, 西华大学工商管理学院, 教授; 北卡罗来纳大学教堂山分校中国城市项目, 访问学者。mint@mail.xhu.edu.cn 


\section{1 生态城市理念的发展与实践历程}

与城市规划的发展历程类似, 生态城市理念也经历了从 构想和概念的提出, 到目标的细化和指标体系的构建, 再到 侧重实践和具体行动的演进过程。在这一过程中, 生态城市 的内容也从人居环境改善向经济转型、社会治理等方面拓展, 与城市规划丰富和完善的历程高度吻合。具体来说, 生态城 市理念可以细分为理念探索, 目标设定和初步试点, 指标评 价体系构建以及广泛应用、完善和务实推进四个阶段。

\section{1 理念探索阶段 (1970-1980 年代)}

生态城市概念是在 1971 年联合国教科文组织发起的 “人与生物圈” (MAB) 计划中正式提出的, 在广义上生态 城市被认为是以生态学原理为指导的新型社会关系和新的文 化观, 狭义则是指在生态学原理指导下, 更加高效、和谐、 健康、可持续的人类聚居环境。1975 年, 美国生态建筑学 家理查德 - 雷吉斯特（Richard Register）成立了以 “重建城 市与自然的平衡” 为宗旨的城市生态组织, 成为最早开展生 态城市研究和实践的组织。1 984 年, 雷吉斯特进一步阐释 了生态城市的建设目标, 在其出版的《生态城市伯克利 : 为 一个健康的未来建设城市》(Ecocity Berkeley: Building Cities for a Healthy Future) 一书中明确了生态城市建设的意义和 原则, 即以相对较小的城市规模建立高质量的城市、就近出 行、小规模的集中化、物种多样性有益健康 ${ }^{[1]}$ 。同时, 雷吉 斯特也提出了将伯克利建设成为生态城市的设想。在这一时 期, 保罗 - 索勒瑞（Palo Soleri）在《生态建筑: 按人的形象 设计的城市》(Arcology: The City in the Image of Man) 一书 中也对生态城市的目标进行的阐释, 并率先在美国的亚利桑 那州的阿尔科桑泰 (Arcosanti) 进行了实践。

\section{2 目标设定和初步应用阶段 (1990 年代)}

进人 1990 年代以后, 生态城市的研究进一步系统化和 具体化。1990 年, 城市生态组织在伯克利组织了第一届生 态城市国际会议, 提出要基于生态原则重构城市目标, 标志 着生态城市从理念探索阶段进人目标设定阶段。美国学者罗 斯兰德（Roseland）于 1994 年指出, 生态城市应当包含城市 的可持续发展、优良的技术、健康的社区，社会的生态化等 方面 ${ }^{[2]}$, 澳大利亚建筑师唐顿认为城市生态涉及城市与自然 系统, 城市内部人与人之间, 以及城市与农村社区之间的相 互关系, 更加突出了生态城市建设中的各系统的协调性。生 态城市建设的目标得到扩展和丰富, 从单纯人居环境改善、 土地开发、城市交通规划等扩展到了城市的社会发展、公众 的生态意识和生活方式等方面。
1996 年, 城市生态组织将生态城市理念进一步具体化 为十项原则：(1) 土地开发利用中优先开发紧凑的、多样 的、绿色的临近交通线路的混合型社区; (2) 交通建设中 优先考虑步行、自行车和公共交通等绿色交通设施的需求; （3）修复城市自然环境;（4）建设更加经济适用、便捷安 全的居住区;（5）注重社会的公平性, 改善妇女、移民等 弱势群体的生活状况和社会地位;（6）推动社区花园化建 设, 提升城市绿化水平; (7) 推广废弃物循环利用技术, 降 低废弃物和污染排放;（8）推动生产者循环化改造；（9）倡 导节约、简单的消费方式; (10) 提升公众的可持续发展意 识和环保意识。生态城市建设的十项基本原则与早期的生态 城市理念相比, 建设的目标更加明确, 对实践的指导意义更 强, 更具有操作性。生态城市的目标从最初的反思和理念探 讨逐步落实到实践行动中, 目标与建设行动形成了相对应的 体系。

随着生态城市建设目标的明确, 许多城市和组织开始了 对生态城市理念应用的探索, 建立相应的评价指标体系, 并 开展了初步试点。1993 年, 美国绿色建筑协会 (USGBC) 出台了 LEED 评价体系, 从绿色建筑、科学选址、交通优化、 社会交流等方面对新开发的住宅项目进行评价, 首次将生态 城市理念融人开发项目评价体系。1994 年, 西雅图建立了 更加系统的城市评价体系—Sustainable Seattle, 从社会安 全和公平、生态环境管理和经济活力三个层面对城市可持续 发展能力进行评价, 并在普吉特湾区 (Puget Sound region) 建立区域性可持续发展实验区, 成为了生态城市目标体系和 实践的开端。

\section{3 评价体系构建和广泛应用阶段 (21 世纪初)}

生态城市理念的逐步普及, 使得生态、宜居、可持续 的城市发展理念得到政府和民众的广泛认同, 生态城市探 索和研究的主体逐步从学者转向城市管理者, 生态城市进 人应用和实践的新阶段。在 21 世纪初, 许多城市和组织已 将构建生态城市的目标体系作为生态城市建设的第一步, 用以衡量城市的现状与生态城市目标的差距, 一些城市也 将生态城市作为城市发展战略和规划的重要目标。在此期 间, 出现了阿联酋的 Estidama 指数 (2008)、《机遇之都》 (City of Opportunity) 研究报告、世界银行的全球城市指 数 (Global City Indicator Facility) 等为代表的一系列评价体 系, 评价体系涉及的指标也从 LEED 关于绿色建筑的单一评 价扩展到城市的经济、社会、生态环境、交通和居住条件等 方面, 在指标的选择上也更加重视代表性（specific）、可量 化 (measureable)、可比性 (comparable), 强调评价结果的 客观性和可比性, 生态城市的目标体系较上一阶段更加的系 
统和成熟, 应用性更强。在各种生态城市评价和排名的刺激 下, 纽约、萨克拉门托、波特兰、克利夫兰等城市纷纷出台 以生态城市理念为指导的城市规划, 开展生态城市建设的 实践。

\section{4 完善和务实推进阶段}

随着城市规模的扩大和城市环境问题的加剧, 生态城市 的建设更加复杂, 涉及的主体更加广泛, 而生态城市建设的 行动实践仍然较为碎片化, 以生态社区、绿色建筑为主的城 市生态化改造模式已经难以适应生态城市建设要求, 与系统 的生态城市目标体系更是有较大的差距。与此同时, 城镇化 水平的提升、城市社会的多元化也带来了城市各类主体对城 市发展诉求的增加, 脱胎于理论研究的生态城市目标体系难 以满足公众对城市发展的需求, 对行动的指导性也亟待提升。 针对上述问题, 各个城市也开始反思上一阶段的生态城市建 设,探索更加务实的推进模式。以 “更葱绿的纽约” (Greener NYC) 为代表的城市发展战略和规划在目标体系设定时, 更 加突出目标体系的公众参与性和政策导向性, 强调其提升公 众生态意识、提高公众参与度、协调各类主体等方面的作用 ${ }^{[7]}$, 在推进模式上更加注重系统性, 强调参与主体多元化转变, 强调先进技术手段的运用以及信息化管理, 更加倾向于采用

“目标一行动” 路线的务实推进模式。

\section{2 美国生态城市目标一行动体系的新特点}

随着生态城市理念的不断丰富和完善, 其目标也不再 仅仅局限于城市的生态环境和居住条件的改善, 而是扩展到 城市的经济、社会、交通等各个方面, 现阶段美国的生态城 市建设已成为可持续发展目标下的综合系统, 也更加重视 城市各子系统的融合和协同, 经济发展模式的生态化、社 会公平和活力, 以及中低收人人群的居住环境等建设内容成 为新的侧重点。从生态城市建设目标的实现模式来看, 生态 城市的目标体系最初是作为生态城市理念的具体化, 随后演 变为城市现状的评价和目标体系, 与生态城市建设行动的结 合不断加深, 其功能也由现状的评价转向对建设行动的引导 和评估, 更加强调对行动的指导意义和对政策有效性的评 估。现阶段生态城市的目标体系已经与建设行动进一步结 合, 构成了 “目标一行动” 路线, 突出对行动的指导性和政 策有效性的评价。例如, 纽约在生态城市建设的目标中就将 碳减排目标分解为控制城市蔓延、提高能源清洁度、建筑节 能、可持续发展交通等方面, 并为每个具体目标设定了减排 指标, 同时也为每一个目标的实现设计了具体的政策支撑, 构成了 “目标一行动” 路线, 以便于生态城市目标的落实和 实现 ${ }^{[7]}$ 。

\section{1 强调经济发展模式的生态化转型}

城市的资源消耗和生态环境状况与城市的产业结构和经 济增长模式紧密相关, 因此美国的生态城市建设也从单纯的 生态人居环境的改善转向经济增长模式的转型, 注重以创新、 人力资本驱动城市经济增长。在设定生态城市发展目标时, 许多城市也不再局限于追求经济总量、速度, 而是更加注重 经济发展的竞争力和稳定性。波士顿、旧金山等城市将增加 智力资源、营造良好的创业孵化环境作为生态城市建设的重 要目标, 并选择受教育程度、科研机构数量、专利增长率、 创业服务企业数量等指标来衡量城市创新能力和技术转化能 力。西雅图用城市的就业集中度、满足基本需求的工作时间 等指标来衡量城市经济发展的多样性和稳定性, 以确保城市 在产业转型升级中更具灵活性, 避免因经济波动造成城市的 税收和就业减少, 从而使城市保持经济发展活力和竞争力。 文化创意产业与个性化、多元化的消费趋势相契合, 具有产 品附加值高和资源环境消耗低的优势, 是城市产业结构转型 升级的主要趋势, 纽约、芝加哥等城市都将发展文化创意产 业作为城市发展的目标, 并选择公众艺术参与度、文艺组织 密度等指标评价文化创意产业发展环境, 引导城市产业结构 的调整。

针对经济发展模式生态化转型的目标, 美国许多城市在 推动生态城市建设中都有配套的经济发展政策。旧金山就通 过增加公共研发投人、建立公共研发机构, 营造良好的创新 创业氛围，通过整合周围区域的市政交通、投资公司、公共 管理部门, 共同构建创新协作联盟, 推动区域协同创新。北 卡罗来纳州的达勒姆市支持专业的孵化服务企业为创业者提 供金融、法律、猎头和市场营销等服务。纽约、洛杉矶和奥 兰多等城市依托城市的艺术中心, 集聚电影制作、主题公园、 创意文化街区等文化创意产业, 培育以创新创意驱动的产业 发展新模式。

\section{2 注重社会进步对生态城市建设的作用}

现阶段生态城市建设的关注重点不再仅仅局限于城 市生态环境的改善, 而是进一步扩展到社会公平和居民福 祉, 更加重视社会公平、社会活力在促进城市可持续发展 中的作用, 强调城市环境与社会系统的共同进步。现阶段 的美国生态城市目标体系中反映社会公平性和社会交流等 方面的指标权重不断增加, 以纽约的城市发展规划 “一个 纽约” (OneNYC) 为例, 该规划将城市的公平性和安全 性单独作为城市发展的四大愿景之一, 在经济发展、环境 保护和宜居性三大愿景中也进一步强调了就业、公共绿 地、教育, 以及社区交流等方面的公平性和可得性 ${ }^{[10]}$ 。除 了重视社会公平性, 美国生态城市规划还将提升社会活力 
纳人生态城市建设的目标体系, 纽约使用遮蔽的绿道比 例、居住区一定范围内的公共设施数量等指标来反映社会 交流的活力, 西雅图、亚特兰大设定了城市公园和开敞空 间的数量和投人目标，来促进居民的社会交流，巴尔地摩 设置了城市节庆活动的频率和资金投人目标，促进城市的 节庆活动。

针对社会进步的目标体系，美国在生态城市建设中也增 加了对应的行动集, 在促进城市公平方面, 西雅图实施了“大 众图书馆” (Libraries for All) 项目, 扩大城市图书馆的覆盖 辐射范围, 达特茅斯建立医疗机构评价系统和远程医疗系统, 一方面提升医疗机构的整体水平, 另一方面促进医疗资源的 共享。在增进社会交流方面, 纽约出台了刺激和规范娱乐空 间建设的规划条例，鼓励开发商或个人营建更多的公共休息 空间，政府也可以通过购买或支付租金为城市公共休憩空间 预留后备土地, 罗利市要求开发商按照街道景观指导方案进 行开发, 拓展城市居民的交流空间, 威斯康辛州的贝菲尔德 (Bayfield) 向消费者征收 1\% 的额外费用，建立支持当地的 节庆活动的专项基金。

\section{3 突出以人为本的城市建设理念}

现阶段生态城市的目标体系除了社区生态化改造和绿色 建筑等方面的目标外, 还更加强调以人为本, 重视面向中低 收人人群的经济适用房和保障性住房建设。生态城市建设的 目标体系中不仅设置了保障性住房的数量指标, 而且还考虑 中低收人人群的居住需求, 逐步增加了对住房选择的多样性、 便捷性和申请难度等效用指标考核。针对中低收人人群的居 住需求的差异性, 波特兰就将经济适用房的多样性作为宜居 性的重要方面, 衡量经济适用房体系满足不同目标人群需求 的能力 ${ }^{[9]}$, 萨克拉门托将经济适用房一定范围内的基础设施 数量、就业机会和公交站点数量等作为宜居性的考核标准, 以保证经济适用住房的使用者享有较好的就业机会、基础设 施和公共交通服务, 经济适用房的申请周期、申请流程等都 可能成为中低收人人群获取经济适用房的壁垒, 波特兰和金 县 (King County) 就将平均申请等待时间作为衡量住房保障 系统的重要指标。

针对这一目标体系, 美国许多城市都在生态城建设中采 取了一系列改善中低收人人群的居住条件的行动措施。西 雅图对包含有保障房的开发项目开辟审批绿色通道, 简化 审批流程, 美国马塞诸萨州的法尔茅斯 (Falmouth) 强制要 求所有新建或再开发项目都要包含至少 $10 \%$ 的保障房。波 特兰、萨克拉门托等城市均出台了房价和租金的监管政策, 并降低了环卫、下水管道等市政设施的费用，降低居民的 居住开销。

\section{3 美国生态城市建设的新趋势}

生态城市的目标体系的变化也带动了生态城市建设行动 的演进, 美国新一阶段的生态城市中, 呈现出建设行动更加 系统化、参与主体更加多元化、技术和手段更加先进、运行 管理更加信息化的新趋势, 与生态城市的目标体系形成了更 有针对性的 “目标一行动” 推进模式。

\section{1 建设行动更加系统化}

生态城市建设初期多以生态社区、绿色交通、绿色建筑 等局部的城市生态化改造为主, 对城市环境的系统改善较为 有限。目前许多生态城市建设者已经意识到, 必须综合考虑 城市的经济、社会、交通、生态环境和住房等系统的相互作用, 在更广的层面整合城市各个系统, 协同推进生态城市建设, 才能实现生态城市的建设目标。在缓解交通压力方面, 美国 多个城市都将交通规划与城市规划相衔接, 鼓励公交导向的 开发模式 (TOD), 从而优化生产生活空间布局, 降低通勤 距离和成本, 伯克利市提高公交线路临近地区的开发强度和 容积率, 鼓励在公交道路临近地区进行高密度和商住混合开 发, 奥斯汀、丹佛和西雅图等城市为临近道路的地块制定了 更加灵活的融资方案和资金扶持计划, 鼓励开发商优先开发 交通线路附近土地, 华盛顿通过税收减免等措施鼓励中小型 企业在交通站点附近办公。在改善居住条件方面, 丹佛市将 经济适用住房开发与交通线路规划相衔接, 成立了专用的收 购基金, 对当前和未来交通廊道附近资产进行战略性收购, 提高经济适用住房的交通便捷性, 西雅图和萨克拉门托都将 促进高密度和混合式开发与基础设施改造相结合, 完善经济 适用住房的基础设施配套。在增加公共服务供给方面, 佛罗 里达州将学校建设与住宅项目开发相结合, 要求新的开发项 目中, 学校等设施必须到位或已经列人建设日程, 才可以获 得建设批准, 强制新建项目进行教育资源配套, 美国的 “到 校安全线路” 项目, 则是将绿色交通体系建设与学校布局相 结合, 通过建立人行道路网、路边自行车道, 完善学校附近 交通安全设施等手段, 倡导安全、低碳的到校方式。在生态 环境改善方面, 波特兰将城市规划与生态环境本底相结合, 通过发行政府公债, 购买规划中的绿色空间的地产 ${ }^{[9]}$, 北卡 州的金斯顿 (Kingston) 通过政府买断的方式, 对洪泛区内 的建筑进行拆除和改造, 将其转化为绿色空间。

\section{2 参与主体更加多元化}

随着生态城市建设的进一步深人, 其涉及的主体更加 广泛, 建设行动也更加专业和具体, 政府为主导的生态城市 建设模式一方面难以承担更加专业和复杂的生态城市建设任 
务, 另一方面也难以满足城市各主体的诉求。因此, 美国在 现阶段的生态城市建设中, 更加注重参与主体的多元化, 通 过动员公众、企业、社会组织等主体参与生态城市建设, 减 轻政府在生态城市建设中的负担, 使其能专注于生态城市建 设的管理和协调, 也通过多方主体的参与保证生态城市建设 能够满足各类主体的利益和诉求, 降低推进的阻力。

美国在新一轮的生态城市建设中, 更加注重专业组织和 市民组织的作用, 将技术推广、行业监督等更加专业和具体 的任务交由专业组织实施, 将决策和沟通等涉及多方利益的 任务交由市民组织分担。北卡罗来纳州通过可持续能源协会 为能源使用者提供节能技术支持、安装自动温控装置、更换 老化或者低效的设备, 是节能技术推广和设备改造的主要执 行者。同时北卡可持续能源协会也是当地再生能源生产标准 (REPS) 的制定者和监管者, 通过设定清洁能源或生物质 燃料发电比例等手段, 敦促能源生产企业使用清洁能源。波 特兰在制定生态环境治理方案时就鼓励和引导市民组织参 与, 并在工程师和技术人员的技术支持下, 实现项目推进由 政府和市民组织共同主导，极大地提升了各主体参与生态城 市建设的积极性, 减小了项目实施的阻力 ${ }^{19]}$ 。

企业是城市建设、运行中的重要主体, 企业的参与和行 为的规范一直是生态城市建设的重要内容。美国罗利市就为 开发商指定了街道景观指导方案, 引导其开发行为, 纽约为 增加城市的公共休喤空间, 也专门出台了规划条例, 鼓励和 规范开发商的行为。加利福尼亚的山景城 (Mountain View) 则是由企业主导生态城镇的规划、建设, 充分利用企业商业 开发的优势, 推动城镇的建设与经济发展相融合。

志愿者和社区服务组织由于其灵活性强和覆盖范围广的 特点, 越来越受到生态城市建设者的重视, 美国在城市的医 疗和社会保障服务中就广泛引入社区组织和志愿者, 美国威 斯康星州的密尔沃基市就将社区流动医疗车、医疗服务志愿 者作为健康信息收集、基础诊断和初级保健护理的主力, 用 以提升城市医疗服务的覆盖范围。

\section{3 技术和手段更加先进}

生态学、社会学等学科交叉产生的研究成果为生态城市 建设提供了更加先进的技术和手段, 现阶段的生态城市建设 更倾向于应用最新研究成果来设计生态城市建设的方案, 提 高建设行动的成效。在城市环境治理方面, 具有持续优势和 更显著成效的环境最优治理手段（Environment BMP）已经 被广泛用作生态城市建设行动的质量控制标准，美国波特兰 实行的绿色街道项目就是一种环境最优治理手段, 通过采用 渗水地、透水路面等绿色基础设施, 该项目能在运行中减 少 $80 \%$ 的峰值水量, 过滤 $90 \%$ 的悬浮物 ${ }^{[9]}$ 。美国能源部推
广的“清凉屋顶” (Cool Roof) 项目, 通过新型涂料减少房 屋的热量吸收, 从而降低空调的使用频率, 实现缓解城市热 岛效应和用电高峰的目的。在大气污染治理方面, 美国运用 大气污染扩散规律研究的研究成果和污染物追踪技术, 在对 城市及周边地区的大气变化和天气情况分析的基础上，通过 建立大气污染物扩散模型，找出工业污染源、道路等大气污 染的扩散路径，并据此优化居住用地、生态空间布局。在城 市自然灾害预防方面，美国环保局实施了“国家城市径流项 目”, 对城市径流量、峰值水量进行检测, 为城市制定雨水 管理和防汛方案提供依据。在社会治安方面, 美国的孟菲斯 市率先在高密度和大人流量的市区采用了环境设计预防犯罪 (CPTED), 应用心理学研究的成果, 通过对街区的灯光、建 筑设计等环境要素的优化, 降低犯罪意识, 增加社区安全性。

\section{4 运行管理更加信息化}

信息技术手段的进步使得城市运行的动态监测、信息整 合成为可能, 数据分析和处理也为评估生态城市建设行为, 预判生态城市建设方向提供了技术支撑。现阶段许多城市已 经将信息化和生态化协同推进作为生态城市建设的重点, 将 信息技术广泛应用于住房、交通、社会管理等领域, 推动城 市资源的高效配置和整合，实现城市的运行效率和资源利用 效率的提升。在居住条件改善方面，奥斯汀、丹佛和孟菲斯 将经济性住房纳人城市的地理信息系统, 优化经济适用住房 的空间布局。在保障性住房申请方面, 西雅图通过增加跟踪 时间、核实收人水平、设置年度变更上限等方式对申请名单 上的低收人人群进行动态管理, 并建立潜在的经济适用住房 申请者信息的收集系统，优化经济适用性住房的申请审批系 统, 减少申请难度和所需时间。在绿色交通方面, 纽约采用 集自动信号系统、联合票务系统和车辆实时信息为一体的智 能公交系统，实现公共交通信息的实时更新，旧金山等城 市还建立了自行车专用的智能交通信号系统 “绿波” (Green Wave)，运用信息技术提高自行车出行的便利性和安全性。 在公共服务方面，西雅图的“大众图书馆”项目引人图书馆 资源的数字化共享机制, 将手机与图书馆的服务和资源相 连接, 推动图书馆由信息提供者向知识交互和创新中心的 转变。在医疗服务方面, 美国广泛运用远程医疗技术, 通 过使用可视化通讯技术，主治医生能够通过视频会议等方 式与专家交流, 减少专家预约和交通时间, 提高医疗服务 的质量和覆盖面。

\section{4 结语及启示}

我国自提出“生态市建设指标” 以来, 已经有超过 $90 \%$ 的地级市将 “低碳生态城市” 作为建设目标 ${ }^{116]}$, 深圳 
和天津将绿色交通、绿色社区和绿色建筑作为生态城市建 设的重点, 并建立了生态城市评价体系; 北京的延庆和密云、 河北保定市和山东德州市将新能源开发利用、生态修复工 程作为生态城市建设的重要突破口；长沙和东莞则通过建 设生态城市先导区和生态园区探索生态城市建设路径 ${ }^{[16]}$ 。 从目前生态城市建设的目标和实践来看, 我国生态城市建 设处于评价体系构建和应用阶段向完善和务实推进阶段的 过渡时期, 仍然存在经济生态化转型与城市规划和开发不 同步、环境建设和资源节约的参与主体单一、公共交通与 城市规划缺乏整合和衔接、保障性住房的建设和分配制度 不完善、社会交流和公共服务配套重视不足等问题。从美 国现阶段生态城市目标体系和建设行动的特点和趋势来看, 我国生态城市建设应当从以下五个方面进行调整和创新, 一是以创新驱动和创意产业培育为重点, 推动经济生态化 转型; 二是以公众参与和技术应用为重点, 完善生态环境 的实现机制; 三是以空间优化和交通设施配套为重点, 构 建绿色便捷的交通体系; 四是以结构优化和政策配套为重 点, 加强保障性住房建设; 五是以提升公共服务效率和增 进社会交流为重点, 促进社会和谐稳定。UP

\section{参考文献}

[1] RICHARD R. Eco-cities: Making cities sustainable is a crucial challenge[C] // A quarterly for human sustainable culture. Oakland: Context Institute, 1984.

[2] ROSEIAND M. Dimensions of the future: an eco-city overview. eco-city dimensions[M]. Gabriola Island: New Society Publishers, 1997.

[3] SKAA A P, ZAWADZK I, et al. Evaluation of the bioindicator suitability of Polygonum aviculare, in urban areas[]]. Ecological Indicators, 2013, 24(1): 552-556.

[4] KENNEDY S, SGOURIDIS S. Rigorous classification and carbon accounting principles for low and zero carbon cities[]]. Energy Policy, 2011, 39(9): 5259-5268.

[5] GOTTSCH ALK D, ROUSE D. Sustaining places : best practices for comprehensive plans[M]. London and New York: Routledge, 2015.

[6] BARRY C, ROGER W Caves. planning in the USA: policies, issues, and processes [M]. 4th ed. London and New York: Routledge, 2014.

[7] NYC Mayor's Office of Sustainability. Local Governments for Sustainability(ICLEI). Case study: New York City's greener, greater buildings plan[EB/OL]. (2014-12-10)[2017-9-10] http://www.nyc.gov/html/gbee/ downloads/pdf/greener_greater_buildings_plan. pdf.

[8] BERKE P, GSDSCHALK D. Searching for the good plan: a meta-analysis of plan quality studies[J]. Journal of Planning Literature, 2009, 23(3): 227-240.

[9] Oregon Metro Government. Metro's Regional Framework Plan(RFP)summary of 2040 growth concept[EB/OL]. (2014-12-19)[2017-09-10]. http://www.oregonmetro.gov/sites/default/ files/01132011_regional_ framework_plan_2011_update_summary_of_2040_growth_concept.pdf.

[10] The City of New York. One New York - the plan for a strong and just city[EB/OL]. (2015-12-13)[2017-09-10]. http://www.nyc.gov/html/onenyc/ downloads/pdf/publications/OneNYC.pdf.

[11] 宋彦, 唐瑜, 丁国胜, 等.规划文本评估内容与方法探讨一以美国城 市总体规划文本评估为例 [J]. 国际城市规划, 2015(S1): 71-76.

[12] 章征涛, 宋彦, 阿纳博. 查克拉博蒂. 公众参与式情景规划的组织和实 践一一基于美国公众参与规划的经验及对我国规划参与的启示 $[J]$. 国 际城市规划, 2015(5): 47-51.
[13] 黄肇义, 杨东援。国内外生态城市理论研究综述 [J]. 城市规划, 2001(25): 59-66.

[14] 罗震东, 何鹤鸣, 张京祥. 改革开放以来中国城乡规划学科知识的演 进 [J]. 城市规划学刊, 2015(5): 30-38.

[15] 杨保军, 张菁, 董珂. 空间规划体系下城市总体规划作用的再认识 [J]. 城市规划，2016, 40(3): 9-14.

[16] 中国城市科学研究会. 中国生态城市发展现状与态势 [EB/OL]. (2013. 06-25)[2017-09-10]. http://www.docin.com/p-1700830649.html..

[17] 张文博, 邓玲. 基于目标——行动路线的生态城市实现路径研究 [J]. 经 济问题, 2017(8): 105-110.

[18] 田敏, 宋彦、宜居社区评价指标比较研究 [J]. 经济体制改革, 2016(3): 182-188.

(本文编辑：秦潇雨) 